\title{
Problems in Breast Surgery: A Repair Manual
}

\author{
Jack Fisher and Neal Handel, ISBN-13: 978-1576262597, ISBN-10: 1576262596, CRC \\ Press, 2014
}

David M. Otterburn

Received: 5 January 2015/Accepted: 8 February 2015/Published online: 18 March 2015

(C) Springer Science+Business Media New York and International Society of Aesthetic Plastic Surgery 2015

Problems in Breast Surgery: A Repair Manual brings a new twist to plastic surgery education, by describing how to manage difficult revision problems in aesthetic and reconstructive breast surgery in the form of an instruction manual. Jack Fisher attributes the idea for the book to his life-long passion of making model trains. Each train came with an instruction manual describing in step-by-step instructions how to build or fix the model. He used this seed of an idea to create the format for this quite exceptional book. He, along with his co-editor Neal Handel, has assembled an impressive team of 30 internationally known plastic surgeons to contribute representative cases and to provide step-by-step guides on how to manage complex and simple defects of the breast.

The topics covered in the book include breast augmentation, mastopexy, reduction mammoplasty, breast reconstruction and nipple areola reconstruction. Each section is then subdivided into post-operative complications and unsatisfactory aesthetic outcomes. There are multiple individual chapters within each subgroup, generally with a variety of different authors commenting on a chapter in each subgroup. The individual chapter starts with a case description, followed by an anatomic description, an analysis of the problem and a description of the technique used to correct the problem. The chapter ends with post-operative photographs and a critical analysis of the results achieved, along with a summary of the "Teaching Points".
The beauty of the book is that the "repair manual" format standardizes each chapter in a very readable and digestible way. A few poorly written chapters can sometimes hamstring a textbook's readability, but this standardized format increases the reader's ability to retain the information by adding repetition and structure to the learning. Of course, the book is not designed to be read cover to cover; after all it is a repair manual. However, it does provide a comprehensive education on reconstructive breast surgery theory and technique.

This one volume, 800-page book is beautifully illustrated with pre- and post-operative pictures, surgical markings, intraoperative pictures and cartoons. For ease of access to its contents, the book can be used with a Vital Source bookshelf account, and can be accessed online or downloaded to read offline. Although the structure of the book is not completely original (it in some ways reminds me of John Cameron's Current Surgical Therapy), i have not seen such a unified format in a book, nor have $i$ seen this format used before in a plastic surgery textbook.

Overall, the book will make a fantastic addition to any plastic surgery library, and should be considered by all, but especially for junior attendings that are focusing on breast surgery.

Conflicts of interest The author declares that he has no conflicts of interest to disclose.

D. M. Otterburn $(\square)$

Weill Cornell Medical College, 450 E. 61st St, New York, NY 10065, USA

e-mail: dmo9004@med.cornell.edu 